\title{
Lack of workplace risk assessment as a predic- tor of adverse health effects for teleworkers - results from the survey on Life with COVID-19 in Latvia
}

\author{
Linda Matisane ${ }^{1, *}$, Linda Paegle ${ }^{1}$, Ivars Vanadzins ${ }^{1}$, and Asnate Anna Linde ${ }^{1}$ \\ ${ }^{1}$ Riga Stradins University, Institute of Occupational Health and Environmental Health, Riga, Latvia
}

\begin{abstract}
Workplace risk assessment is one of the key tools for improving occupational safety and health conditions. However, providing risk assessment for teleworkplaces in the COVID-19 pandemic-related restrictions has been a challenge for employers. The objective of this study was to identify the frequency of implementation of workplace risk assessment for teleworkplaces and the association between it and self-reported health complaints among teleworkers during the 1st emergency state of the COVID-19 pandemic in Latvia. Teleworkers were recruited using a non-probability sampling (snowball sampling) method and social media advertisements. To obtain data that is representative of the demographic profile of the working population in Latvia, the sample was weighed based on gender and age. Out of 447 teleworking respondents included in our analysis, only $20.3 \%$ have mentioned that their employer had assessed the teleworking conditions (additional 8.1\% reported partial assessment). Workers who have reported lack of risk assessment more often have health related complaints - e.g., pain longer than three days $(26.9 \%$ with risk assessment versus $73.1 \%$ with no risk assessment), sore eyes $(24.4 \%$ versus $75.6 \%)$ and anxiety $(21.8 \%$ versus $78.2 \%)(p<0.001$ in all cases, except for pain). Increased incidence of occupational musculoskeletal diseases and burnout can be predicted in coming years in Latvia. Good practise examples should be gathered and promoted; guidelines for labour inspection should be developed in order to cover supervision of teleworking workplaces.
\end{abstract}

Key words - workplace risk assessment; telework; distance work; home office; health effects.

\section{Introduction}

\subsection{Telework and COVID-19}

As a response to the worldwide COVID-19 pandemic and depending on the local situation, governments have taken different measures to reduce the spreading of COVID-19, which also included the compulsory or voluntary transition to telework when possible. In Latvia, during the first wave of the pandemic full lockdown was not implemented, therefore, telework as a work organization method to reduce number of possible contacts was only strongly

\footnotetext{
*Corresponding author: linda.matisane@ rsu.lv
} 
advised. From 12 March 2020 when the first emergency state was announced until the first quarter of 2021 the percentage of workers working from home in Latvia has been changing between $8.9 \%$ of the total workforce when COVID-19 restrictions were mild, and $22.6 \%$ when COVID-19 restrictions were rather strict [1].

The definition of telework is defined in the national Labour Protection Law that transposes requirements of the Council Directive 89/391/EEC of 12 June 1989 [2,3]. According to this law, telework is defined as "the type of work which could be done in the premises of the employer, but on regular basis is done outside these premises using information and communication technologies" [2]. A rather similar definition can be found in literature, e.g., "telecommuting is defined organization and/or execution of tasks performed away from the central offices or production facilities of organizations for a certain period in pre-established work schedules, information and communication technologies are used to establish communication between workers and to respond to the demands of the organization remotely" [4].

\subsection{Workplace risk assessment for distant workplaces}

A workplace risk assessment is one of the key tools for improving occupational safety and health conditions at work. It plays an important role not only in protecting workers but also in protecting businesses [5]. Concerning workplace risk assessment, the Council Directive 89/391/EEC of 12 June 1989 on the introduction of measures to encourage improvements in the safety and health of workers at work states that the employer shall be in possession of an assessment of the risks to safety and health at work, including those groups of workers exposed to particular risks, and decide on the protective measures to be taken and, if necessary, the protective equipment to be used [3]. These legal provisions are not new, as the Member States had to bring into force the laws, regulations and administrative provisions necessary to comply with this Directive by 31 December 1992. For Latvia, these general provisions are applicable since 2002 when the new Labour Protection Law came into force [2].

Already before the COVID-19 pandemic, it has been recognized that management of occupational safety and health conditions in case of telework is more difficult due to the lack of the possibilities to monitor and control the teleworking arrangements [6]. When the office worker is working in the premises of the employer, many of the workplace hazards are managed through workplace risk assessment and infrastructure as the employer purchases, arranges the computer workstations and other furniture, and also invites occupational safety and health experts and/or ergonomists to advice on working conditions [7,8]. COVID-19 epidemiological restrictions have deepened these problems - the transition to telework was massive and forced by the government restrictions, and it has made teleworkers use workplaces that do not comply with basic ergonomic principles $[8,9]$.

However, the rapid growth of telework in time when the COVID-19 restrictions are in force had raised several social and legal issues regarding employer's responsibility for the safety and health of teleworkers in the virtual workplaces in their home offices [7]. Even though it may be difficult for the employers to carry out their legal obligation - workplace risk assessments - in the current context employers have the same health and safety responsibilities for home-based teleworkers as for any other [6,10].

In general, when discussing methods and approaches used for workplace risk assessment in telework, it is explained that the principles are the same as for any other workplaces [11]. Some employers and occupational safety and health experts were looking for other possibilities for workplace risk assessment without visiting the homes of the workers, which was prohibited because of the COVID-19 epidemiological restrictions. They conducted virtual site-checks, used self-addressed checklists to be filled in by workers, etc. [6,12]. 


\subsection{Work-related health effects of teleworkers}

When discussing typical health issues related to working in offices, the relationship between the use of computers and the development of musculoskeletal disorders has been welldocumented [7,13]. Pain in the neck and back [14,15], sore wrists and tendon pain in the wrists and fingers $[14,15]$ have already been associated with telework. Surveys on musculoskeletal disorders in teleworkers report that almost half of the respondents have experienced work-related pain [15].

Sore and tired eyes are another problem frequently reported by office workers [14]. Telework also influences mental wellbeing which has been linked with such aspects as personal isolation, conflict of work-life balance [4], greater responsibilities and higher demands on self-management [16], increased stress levels [15,17], longer working hours, including work also in leisure time [15].

To sum it up, telework during the COVID-19 pandemic has been a huge challenge for employers to fulfil their legal occupational safety and health obligations, including assessing workplace hazards for workplaces located in the homes of their workers and providing relevant preventive measures. Therefore, an increased prevalence of work-related health effects might be observed in the coming years in Latvia. Therefore, it seems that workplace risk assessment is even more important for workplaces located in the homes of workers than for workplaces located in the premises of the employers.

The objective of this study was to identify the current situation with the implementation of workplace risk assessment for telework places and the association between the level of implementation of the workplace risk assessment and self-reported health complaints among teleworkers during the first emergency state of the COVID-19 pandemic in Latvia. In order to reach the objective of this study, the following tasks were formulated: 1) To analyze and explain performance of the employers related to workplace risk assessment. 2) To analyze the association between the implementation of the workplace risk assessment and self-reported health complaints. 3) To provide conclusions to reduce the burden of possible health effects resulting from telework.

This research is original. It provides additional evidence on the need for more active implementation of workplace risk assessment at the company level in order to protect teleworkers better.

\section{Material and methods}

\subsection{Recruitment and data collection}

A web-survey as an online tool was used to quickly gather information from workers on measures taken by their employers to arrange healthy and safe working conditions in case of telework during the first wave of the COVID-19 pandemic. The data covering the situation during the first wave of the pandemic were gathered between 28 September and 27 October 2020 .

The web survey applied a non-probability sampling method. Survey participants were recruited using a snowball sampling method, social media advertisements as well as direct emails to share the web link of the questionnaire in Latvian. Every single person having access to the internet was able to fill in the questionnaire.

Web-survey started with written information on the purpose of the study, therefore, participants by voluntary proceeding to the questions agreed to participate in the survey. At the beginning of the web-survey, filtering questions were applied to recruit only paid workers who were employed during the previous year. The following exclusion criteria were used: 
working without salary in family businesses, working without salary on a family farm, being on maternity leave, being unemployed persons, being only retired persons, being housewives, being only school-children or students during the survey period. In total, 1823 persons responded to the questions, however, only 1006 respondents answered all questions (response rate- $55.2 \%$ ).

A set of filters and rooting was applied to the questionnaire to adapt the questionnaire to the particular situation of the respondents, e.g., the telework section was asked only to those who reported their work could be done from distance and they worked from home during the first emergency state due to the COVID-19 pandemic. After data cleaning, answers from 447 respondents who had been teleworking during the first emergency state because of the COVID-19 pandemic and had given a certain answer if the employer had assessed their working conditions were included in the analysis.

Survey data were gathered and managed using REDCap (Research Electronic Data Capture) tool. The study was conducted according to the guidelines of the Declaration of Helsinki, and approved by the Institutional Review Board-Ethics Committee of Riga Stradins University (protocol No. 6-1/08/16, 2 July 2020).

\subsection{Study variables}

In total, information on eleven different types of preventive measures offered by the employers to support workers doing their job from home was gathered. The preventive measures to be included in the questionnaire were selected to cover general or COVID-19 related national legal requirements (e.g., on stay-at-home policy, workplace risk assessment, occupational health and safety training) in force during the first emergency state caused by the COVID19. In addition, measures provided by the employers in Latvia, which had been identified as good practice examples by the State Labour Inspectorate and the Institute for Corporate Sustainability and Responsibility and published on the national occupational health and safety website www.stradavesels.lv on 8 May 2020, were included in the questionnaire [18].

For this article, the following statement on preventive measures was used: "My employer found out the conditions where I am teleworking". When the authors of the survey constructed the questionnaire, the statement "My employer found out the conditions where I am teleworking" was included to ask the respondents if their employer has provided any workplace risk assessment for workplace located at the home of the worker. Such wording for the statement was chosen to avoid the use of complicated and/or unclear legal term "Workplace risk assessment" which might not be understandable for the respondents who are not directly involved in occupational health and safety management and might not be familiar with the term. However, when the authors describe the results of this survey in this article, they refer to the term "Workplace risk assessment".

For the above-mentioned statement, to assess the level of implementation of workplace risk assessment, a choice from several answers was possible: "It was necessary and was provided in all cases", "It was necessary, but was provided only in some cases", "It was necessary, but was not provided", "It was not necessary and was not provided". Respondents who answered - "I don't know" (in total 36) were excluded from further analysis.

Three outcome variables of this study were analyzed to evaluate self-reported health effects: self-reported pain longer than three days, sore eyes and anxiety with the new working and living environment and arrangements. Self-reported pain lasting longer than three days during the first emergency state was measured by two questions - at first, only those respondents who reported having pain longer than three days during the previous year were selected. These respondents were asked to answer the question "Did you have pain during the emergency state which was longer than three days?" Several answers were possible: "Yes, more often 
and/or more severe than before", "Yes, frequency and severity were the same as before", "Yes, but less often and/or less severe than before", "No, I did not have". Answers from the respondents who reported having no pain during the previous year and having pain during the previous year, but not having it during the emergency period were combined in one group as respondents not having pain during the emergency period. Respondents who reported "I don't know / hard to say" were considered as missing values and were excluded from analysis (in total 45).

Having sore eyes and anxiety were identified by the following questions "When working remotely, did you have more often sore, tired, dry, etc. eyes?" and "When working remotely, did you feel anxiety with the new working and living environment?" For both questions several answers were possible: "Yes", "No" and "Hard to say". Respondents who reported "I don't know / hard to say" were considered as missing values and were excluded from analysis (in total 33 for sore eyes and 25 for anxiety).

To analyze data, for each self-reported health effect two groups of respondents were created: 1) teleworkers who reported his/her employer has provided workplace risk assessment in all cases and 2) teleworkers his/her employer has provided workplace risk assessment only in some cases or has not provided workplace risk assessment at all, although it was needed.

\subsection{Statistical analysis}

Descriptive analyses (mean, standard deviation) and frequency analyses (percentages, distribution) were used to describe the data. The correlation between the provision of workplace risk assessment and self-reported health effects was analyzed by using binomial logistic regression and calculated as odds ratios (ORs) with 95\% confidence intervals (CIs) in adjustment to gender and age. Gender and age as confounding variables were included in the regression models. Age was divided into the following groups: $18-24,25-34,35-44,45-54$, $55-64$ and $65-74$. The average age of respondents was $42.6+/-10.5(\min 22$, $\max 72$ years), $15.2 \%$ were males and $84.8 \%$ females. Data weights were made by age crossed with gender (in 12 age-gender combinations) and analyzed with statistical software IBM SPSS, version 26 (IBM Corporation, Armonk, New York, NY, USA). Weighting targets included population estimates of the 3rd quarter of 2020 by age groups and gender obtained from the Central Statistical Bureau of Latvia. Only results with applied weights are given in the sections "Results and discussion".

\section{Results and discussion}

In total, $32.0 \%$ of respondents reported pain longer than three days during the first emergency state, including $10.4 \%$ - reporting more often and/ or more severe pain than before, $17.6 \%$ - reporting pain with the same as before frequency and severity, and $4.0 \%$ - having pain less often and/or less severe than before. In addition, $68.0 \%$ of respondents reported no pain $34.5 \%$ of respondents reported having sore eyes, but $35.2 \%$ - anxiety with the new working and living environment.

When looking at the results of the web-survey, only $20.3 \%$ of teleworkers have reported that their employer has assessed the teleworking conditions. Additional $8.1 \%$ mentioned that it was done partially. $27.0 \%$ of respondents have stated that such assessment had not been done although they think that it was necessary. According to our understanding, results showing that $44.6 \%$ of teleworkers believe that such activity is not needed and should not be implemented are surprising. However, this group of respondents is not homogenous - it includes teleworkers who already had an ergonomic home office before the COVID-19 
pandemic, as well as those who believe that workplaces located at worker homes are not the responsibility of the employer, and others [19]. Lack of paying attention to ergonomics while working at home from workers' side and showing no interest from employers' side has already been reported before COVID-19 pandemics [15]. Most probably the situation during the emergency state has worsened as telework was a forced challenge - the priority of the employers was to survive during the COVID-19 crisis and to focus on main business aspects (e.g. paying salaries and rent, ensuring cash flow, apply and use state-provided financial support) $[15,20]$. This has resulted in lack of time to focus on workplace risk assessment; therefore, occupational health and safety (including legal obligations) and wellbeing of workers were not a priority for many employers. Among the other reasons for not providing workplace risk assessment, the authors of the survey would like to mention the lack of clear legal acts and guidance for workplace risk assessment in case of telework, as telework was a new form of work organization of many workers and employers. The first wave of COVID-19 pandemic was very mild in Latvia, therefore, some of the employers believed that telework is only temporary and will not be used after the end of the first emergency state, as there will not be the second wave of the COVID-19. Other employers considered that if a workplace risk assessment is provided for office work carried out in the premises of the employer, then there is no need for additional risk assessment for home offices as hazards are similar [19]. One more problem associated with work from home is related to the privacy of workers associated with checking of the working conditions at homes of the workers. Such activities can be perceived as a request for private data on living conditions to be submitted to the employer or as the surveillance of workers and the whole household from the side of the manager or employer [21].

The respondents who have reported a lack of risk assessment more often have reported all of the studied self-reported health effects $(p<0.001$ in all cases, except for pain longer than three days) where only a tendency was observed $(p<0.05)$. For example, sore eyes were reported only by $24.4 \%$ of respondents whose employer had provided workplace risk assessment versus $75.6 \%$ of those respondents whose employer had not provided workplace risk assessment. For anxiety, the relevant percentage was $21.8 \%$ for respondents with provided workplace risk assessment and $78.2 \%$ for respondents without workplace risk assessment. Although statistically insignificant, a similar tendency was observed also if self-reported pain longer than three days was analyzed (26.9\% of respondents with provided workplace risk assessment and $73.1 \%$ of respondents with not provided workplace reported such pain).

The odds of all analyzed self-reported health effects were significantly increased. Among the respondents who reported no workplace risk assessment, the odds of sore eyes increased 2.64 times and for anxiety odds even tripled. A weaker, but still significant association was found between lack of workplace risk assessment and pain longer than three days (Table 1).

In general, this study shows that workplace risk assessment provided by the employer can reduce the percentage of workers who have complaints related to sore eyes, anxiety, and pain longer than three days. The associations remained strong for sore eyes and anxiety after adjusting for gender and age, but it was not strong for pain longer than three days anymore. After adjustment for gender and age, the association increased for sore eyes but decreased for anxiety and pain longer than three days.

Several reasons for more often self-reported health effects in teleworkers can be mentioned. Usually, home offices are set up by the workers themselves without any external assistance and training [7,22]. Especially at the beginning of the COVID-19 restrictions, when the transition to telework was very rapid, workers used the furniture which was already available at their homes - e.g. coffee tables, ironing boards, kitchen, dining tables, old desks and living room sofas or beds $[7,22]$. In addition, due to the size of the living area, not all workers had a dedicated individual (personal) workstation in their homes therefore they had 
Table 1. The odds of self-reported health effects in association with status of workplace risk assessment.

\begin{tabular}{|c|c|c|}
\hline $\begin{array}{l}\text { Status of workplace } \\
\text { risk assessment }\end{array}$ & Self-reported health effects \\
\hline & OR (95\% CI) & $\begin{array}{c}\text { OR (95\% CI), } \\
\text { adjusted for age and sex }\end{array}$ \\
\hline \multicolumn{3}{|c|}{ Pain longer than three days } \\
\hline Not provided & $1.95^{* * *}(1.03-3.66)$ & $1.82(0.95-3.51)$ \\
\hline Provided & 1 & 1 \\
\hline \multicolumn{3}{|c|}{ Sore eyes } \\
\hline Not provided & $2.64^{* *}(1.44-4.84)$ & $2.81^{*}(1.50-5.26)$ \\
\hline Provided & 1 & 1 \\
\hline \multicolumn{3}{|c|}{ Anxiety } \\
\hline Not provided & $3.01^{*}(1.62-5.61)$ & $2.83^{*}(1.50-5.35)$ \\
\hline Provided & 1 & 1 \\
\hline
\end{tabular}

The reference category is respondents, whose employer has provided workplace risk assessment. $* p<0.001, * * p<0.01, * * * p<0.05$.

to share this workstations with children who had to attend school remotely or partner who was also teleworking during the COVID-19 pandemic [22]. As the solution, setting up shift desks or working in a variety of places throughout the day was typical [22]. Teleworkers also report a lower level of awareness and knowledge about ergonomics and safety issues as they are less likely to receive sufficient ergonomics training while working at home [23]. In addition, telework is a new and non-standard type of employment and work organization, but non-standard employment relationships have already been identified as a challenge for occupational health and safety [24]. Therefore, to avoid the development of health problems in teleworkers, workplace risk assessment is extremely important for workplaces located in home offices, and employers and occupational health and safety experts need advice on the proper implementation of workplace risk assessment for distant workplaces.

The use of web-survey as a non-probability sampling method to gather data quickly from respondents has also some research limitations. To obtain data that is representative of the demographic profile of the working population in Latvia, the sample was considered based on gender and age. The authors were not able to weigh data in terms of education or work experience as such population estimates were not available from the Central Statistical Bureau of Latvia for the study period.

Typically, among other limitations of this sampling method access to the internet and low digital literacy are mentioned, however, workers without the internet cannot telework therefore we do not believe this has much influence as the study population is teleworkers. The questionnaire was available only in Latvian, which can reduce the participant rate of Russian-speaking persons. Taking into account that in most cases teleworkers belong to administrative workers who have to organize documentation in Latvian, we believe that the influence of this limitation should be low.

\section{Conclusions}

Our findings suggest that employers have not sufficiently implemented their legal obligations related to workplace risk assessment in the teleworking situation. The results provide evidence that some consequences can be observed already now - pain longer than three days, 
sore eyes, and anxiety with the new working and living environment are observed more often in teleworkers who work for employers who have not provided workplace risk assessment. As the percentage of teleworkers has dramatically increased during the first COVID-19 pandemic-related emergency state in Latvia, we can predict that increased numbers of occupational musculoskeletal diseases and burnout will be observed in the coming years. It provides additional evidence on the urgent need for more active implementation of workplace risk assessment at the company level to protect teleworkers better. To reduce this burden, good practice examples of workplace risk assessment methods used in Latvia and internationally should be gathered and promoted for employers. In addition, guidelines for labour inspection should be developed to cover supervision of all workplaces including teleworking workplaces.

The authors thank Lāsma Akūlova, Sarmīte Rozentāle, Ieva Grīntāle, Iveta Mietule, Jeḷena Lonska, Lienīte Litavniece, Iluta Arbidāne for technical support. The authors also are grateful to the survey participants.

This research was funded by the National Research Programme of Latvia within the project "Life with COVID-19: Evaluation of Overcoming the Coronavirus Crisis in Latvia and Recommendations for Societal Resilience in the Future" (agreement No: VPP-COVID-2020/1-0013).

\section{References}

[1] Central Statistical Bureau. Remote workers (employees) by age group and by sex (in Latvian). Available: https://stat.gov.lv/lv/statistikastemas/darbs/nodarbinatiba/tabulas/nbl270c-attalinati-stradajosie-darbinieki-darba (assessed on 26.06.2021)

[2] The Republic of Latvia. Labour Protection Law. Available: https://likumi.lv/ta/en/en/id/26020-labour-protection-law (assessed on 25.05.2021)

[3] European Parliament and of the Council. Council Directive 89/391/EEC - OSH "Framework Directive.". Available: https://osha.europa.eu/lv/legislation/directives/theosh-framework-directive/1 (assessed on 7.06.2021)

[4] T.A.M. de Macêdo, E.L.D.S. Cabral, W.R. Silva Castro, C.C., de Souza Junior et al. Work. Ergonomics and telework: A systematic review 66, 777-88 (2020) https://doi.org/10.3233/WOR-203224

[5] International Labour Organization. A 5 step guide for employers, workers and their representatives on conducting workplace risk assessments (2014).Available: https://www.ilo.org/safework/info/publications/WCMS_232886/lang-en/index.htm (assessed on 7.06.2021)

[6] International Labour Organization. An employers' Guide on Working from Home in Response to the Outbreak of COVID-19 (2020). Available : https://www.ilo.org/wcmsp5/ groups/public/---ed $\_$dialogue/---act $\backslash$ emp/documents/publication/wcms $\_745024$.pdf (assessed on 8.06.2021)

[7] S.S. Harrington, B.L. Walkers. J SafetyRes. The effects of ergonomics training on the knowledge, attitudes, and practices of teleworkers 35(1), 13-22 (2004). https://doi.org/10.1016/j.jsr.2003.07.002

[8] S.H. Chong, Y. Huang, C.H. Daisy Chang. J ApplPsychol. Supporting Interdependent Telework Employees: A Moderated-Mediation Model Linking Daily COVID-19 TaskSetbacks to Next-Day Work Withdrawal 105, 1408-22 (2020) https://doi.org/10.1037/ap10000843

[9] A. Belzunegui-Eraso, A. Erro-Garcés. Sustainability. Teleworking in the context of the Covid-19 crisis 12(9), 3662 (2020) https://doi.org/10.3390/su12093662 
[10] P. Huuhtanen. The Social Dimensions of Telework: The Health and Safety Issues for Teleworkers in the European Union (2006) Available: https: //webs.ucm.es/info/seas/estres $\_$lab/informes/Informe $\ \% 20$ europeo $\ \% 20 \mathrm{Health} \backslash \% 20 \backslash$ $\& \backslash \% 20$ Safety $\backslash \% 20 I s s u e s \backslash \% 20$ for $\backslash \% 20$ Teleworkers.pdf (assessed on 11.06.2021.)

[11] European Agency for Safety and Health at Work. Efact 33 - Risk assessment for Teleworkers (2008).Available: https://osha.europa.eu/sites/default/files/publications/documents/en/publications/efacts/efact33/33\%20_risk_assessment_for_teleworkers.pdf (assessed on 11.06.2021)

[12] International Labour Organization ILO, C. Reis, S. Durkin.AusIMM Bulletin, Teleworking during the COVID-19 pandemic and beyond (2018) Available : $\quad$ https://www.ilo.org/wcmsp5/groups/public/—ed_protect/—protrav/— travail/documents/instructionalmaterial/wcms_751232.pdf (assessed on 15.05.2021.)

[13] Eurostat. Health and safety at work in Europe (1999-2007) - A statistical portrait (2010) Available: https://ec.europa.eu/eurostat/web/products-statistical-books/-/ks-3109-290 (assessed on 8.06.2021.)

[14] A. Hedge, T. James, S. Pavlovic-Veselinovic. Int. J. Ind. Ergon. Ergonomics concerns and the impact of healthcare information technology 41(4), 345-351 (2011) https://doi.org/10.1016/j.ergon.2011.02.002

[15] Eurofound and the International Labour Office. Working anytime, anywhere: The effects on the world of work (2017). Available: https://www.eurofound.europa.eu/publications/report/2017/working-anytimeanywhere-the-effects-on-the-world-of-work (assessed on 1.05.2021)

[16] C. Steidelmüller, S.C. Meyer, G. Müller. J. Occup. Environ. Med, HomeBased Telework and Presenteeism Across Europe 62, 998-1005 (2020) https://doi.org/10.1097/JOM.0000000000001992

[17] P.C. Melo, J. de Abreu e Silva. Transportation Research Part A: Policy and Practice. Home telework and household commuting patterns in Great Britain 103, 1-24 (2017) https://doi.org/10.1016/j.tra.2017.05.011

[18] Stradavesels.lv. Technical and organisational measures to limit the spread of COVID-19 in the working environment (in Latvian). Available : http://stradavesels.lv/jaunumi/tehniski-un-organizatoriski-pasakumi-ka-ierobezotcovid-19-izplatisanos-darba-vide/(accessedon 10.06.2021)

[19] Rīga Stradin̄s University; Vidzeme University of Applied Sciences; Rezekne Academy of Technologies. Additional project results No. 31 (2020) Available:http://stradavesels.lv/Uploads/2021/01/05/31_zinojums_c.pdf_ (accessedon 10.05.2021)

[20] International Labour Organization. The impact of the COVID-19 pandemic on jobs and incomes in G20 economies (2020). Available: https://www.ilo.org/global/aboutthe-ilo/how-the-ilo-works/multilateral-system/g20/reports/WCMS_756331/langen/index.htm (assessed on 20.05.2021.)

[21] N. ben Fairweather. J. Bus. Ethics, Surveillance in employment: The case of teleworking. Journal of Business Ethics 22, 39-49 (1999). https://doi.org/10.1023/A:1006104017646

[22] Y. Xiao, B. Becerik-Gerber, G. Lucas, S.C. Roll. J. Occup. Environ. Med. Impacts of Working from Home during COVID-19 Pandemic on Physical and Mental Well-Being of Office Workstation Users 63(3), 181-90 (2021) https://doi.org/10.1097/JOM.0000000000002097 
[23] M.C. Schall, P. Chen. Hum Factors. Evidence-Based Strategies for Improving Occupational Safety and Health Among Teleworkers During and After the Coronavirus Pandemic (2021, online ahead of print). https://doi.org/10.1177/0018720820984583

[24] M.A. Fox, K. Spicer, L. C. Chosewood, P. Susi et al. Environ Int. Implications of applying cumulative risk assessment to the workplace 115, 230-238 (2018) https://doi.org/10.1016/j.envint.2018.03.026 